\title{
Direct Instantaneous Torque Controlled Modular Switched Reluctance Motor Designed for Automotive Applications
}

\author{
Loránd Szabó, Mircea Ruba, Daniel Fodorean \\ Faculty of Electrical Engineering \\ Department of Electrical Machines and Drives \\ Technical University of Cluj-Napoca \\ Cluj-Napoca, Romania \\ Lorand.Szabo@emd.utcluj.ro
}

\author{
Pavol Rafajdus, Peter Dubravka \\ Faculty of Electrical Engineering \\ Department of Power Electrical Systems \\ University of Žilina \\ Žilina, Slovakia \\ pavol.rafajdus@kves.uniza.sk
}

\begin{abstract}
The electrical drive systems used in automotive applications has to be both reliable and of high performance. To fulfill these demanding requirements a modular fault tolerant switched reluctance motor is proposed, which is controlled by means of an effective direct instantaneous torque controller. In the paper both the motor and the control system are described. By simulations the working principle of the drive system is illustrated and its performances are demonstrated.
\end{abstract}

Keywords-switched reluctance motor, modular construction, direct instantaneous torque control, simulation.

\section{INTRODUCTION}

Conventional internal combustion engine vehicles have several electric motors on their board. Modern cars can have more than 100 small and medium sized motors moving the windows, seats and windshield wipers, or driving diverse pumps, etc. These motors have to be reliable, cheap and lightweight.

Moreover, to more improve the reliability, fault tolerance, performances and safety level of the vehicles a tendency to substitute mechanical interfaces between the driver and the vehicle with electronic systems can be observed. These generically called X-by-wire systems consist of the driver operating unit (throttle pedal, brake pedal, gear selector, steering wheel, etc.) whose electrical output is processed by advanced control systems that manage the powertrain, braking and steering activities via electrical motors or actuators [1].

Permanent magnet (PM), brushless de (BLDC) and switched reluctance motor (SRM) drives are the most important candidates for such automotive applications. Each motor and the corresponding drive have some technical advantages and drawbacks, depending upon the actual application.

Several of the automotive applications of the electrical drive systems are safety-critical, as the above mentioned $\mathrm{x}$-by-wire systems. For these applications the continuous or reduced operation of the drive system must be ensured even if a fault occurs in the motor or in the power converter. Parallel redundancy of the electrical drive system can be applied, but this solution implies high costs [2].

Fault-tolerant electrical drive systems are cost effective solutions without sacrificing their post-fault performance. Therefore they are desirable also for safety-critical automotive applications [2].

The SRM is inherently the most fault tolerant electrical machine, because it can continue operating and producing torque in certain limits also with one or more faulty coils or phases [3], [4], [5]. This is due in a large part to its independent concentrated windings. Its brushless and PM free simple construction enables a maintenance free utilization also in high temperature, dusty, dirty and vibrations exposed harsh environments of the vehicles [6].

Combining the fault tolerance increasing solutions with the modular construction concept a novel SRM was developed, which is high reliable and quickly repairable.

To fulfill the high requirement imposed by the automotive industry the modular SRM has to be controlled by a high performance system, which is able to also reduce significantly the torque ripples of the SRM. For this purpose an advanced control strategy is proposed, which is based on estimating and controlling the instantaneous torque developed by the motor.

\section{THE MODULAR SRM}

The stator of the proposed modular SRM is built up of independent modules. Each one has an E-type iron core and o coil wound on its yoke. The modules corresponding to a phase are placed diametrically opposed in the stator. Between the neighboring modules a non-magnetic spacer is placed to assure the adequate shift of the modules and a good magnetic separation.

The four-phase variant has 8 modules. The entire modular stator construction is tightened by 16 rods, 2 passing 
through each module. The stator is placed between two end shields. The conventional rotor has 14 poles and it is built of laminations. The construction of the SRM is given in Fig. 1.

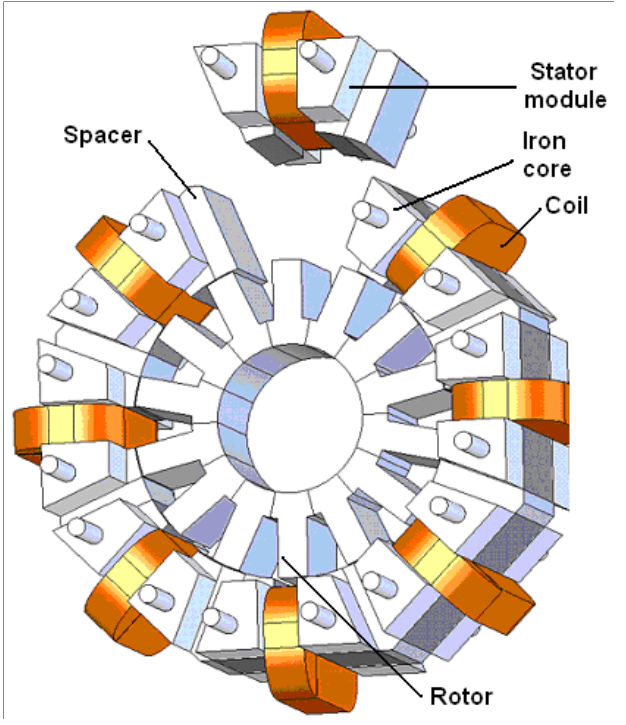

Fig. 1. The modular stator SRM

One of the common fault tolerance increasing solutions is the division of the phases into individual coils, called channels [7], [8], [9]. This way a fault of a channel will not influence the operation of the other channels of the same phase or of other phases. This solution was used also in the case of the modular SRM. Hence, one phase of the machine is compound of two coils from diametrically opposed modules, connected in series or in parallel.

Due to the specific construction there is no mutual coupling between adjacent coils [10]. The drawback of this solution is that a more complex power converter is required, having as many converter legs as channels [11], [12].

The adopted modular stator topology allows for an easy and quite low cost manufacturing and assures the possibility of a fast replacement of a damaged module in case of a coil failure [13].

The main specifications of the sample modular SRM taken into study are given in Table I.

TABLE I. SPECIFICATIONS OF THE MODULAR SRM

\begin{tabular}{|l|c|}
\hline \multicolumn{1}{|c|}{ Item } & Value \\
\hline Rated power & $350 \mathrm{~W}$ \\
\hline Rated voltage & $300 \mathrm{~V}$ \\
\hline Rated current & $6 \mathrm{~A}$ \\
\hline Rated medium torque & $5 \mathrm{~N} \cdot \mathrm{m}$ \\
\hline
\end{tabular}

\section{THE Direct InSTANTANEOUS TORQUe CONTROL}

One of the main disadvantages of the SRMs, and also of the particular modular SRM in discussion, is their significant torque ripple. These can generate significant vibrations and noises, hence creating discomfort for the driver. All these are absolutely undesirable in automotive applications.
In the literature several methods of SRM torque smoothening methods are cited [14], [15], [16]. These all require complex control [17], [18], accurate torque and rotor position measurement [19] and complex current regulation techniques [20]. Current profiling [21], [22] and torque sharing [23], [24], methods are just two solutions that can be used for minimizing the SRM torque ripples.

A common conclusion can be drawn upon studying these methods, namely that as the complexity of the control strategy is increased the losses in the SRM are also increased. Therefore a novel method was applied, the direct instantaneous torque control (DITC) [25], [26]. This has to be used where the losses has to be low as possible, the system response has to be fast and accurate, and the generated torque must be smooth [27].

The main advantage of the DITC is the lack of minor current loops and of PI or PID controllers, which always need precise tuning. The torque of the SRM is controlled directly by using a specific digital hysteresis controller. On the other hand as the phase currents are not controlled, overheating of the power switches can occur. At high speeds and when the currents are very high the falling to nil of the current could be not enough fast and negative torques could be generated by a phase.

The instantaneous torque developed by the SRM needs to be known at each time step. The precise measurement of the instantaneous torque is difficult and expensive. A more effective approach is by estimating the torque.

In the literature basically four methods are cited for torque estimation. These methods are based on look-up table, interpolation, analytical approach and artificial neural networks (ANN) [28]. For the DITC method the look-up table approach seems to be the best suited [25], [29].

For estimating the torque from the measured current and rotor position the static torque versus current and angular position is required. The values of this characteristics are stored in a 2D look-up table, which can be obtained via measurements or finite elements analysis (FEA) of the SRM [30], [31]. Knowing at each time step the actual current and the rotor position the torque of the SRM can be found by a simple looking in the table. It should be mentioned that separate look-up tables has to be computed for each SRM variant.

The simple block scheme of the DITC system is given in Fig. 2 [16].

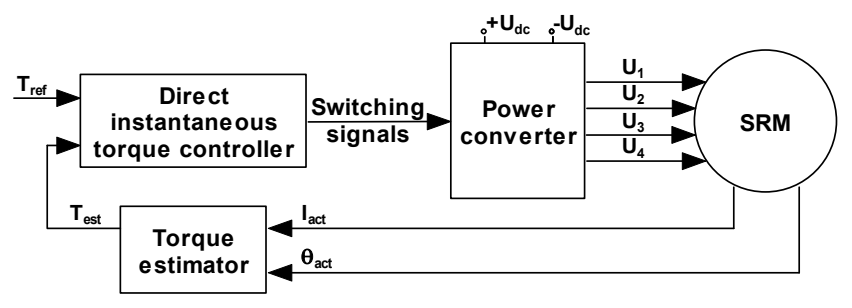

Fig. 2. The block scheme of the DITC system [16] 


\section{THE DITC OF THE MOdULAR SRM}

The proposed hysteresis torque controller uses two different hysteresis bands, one larger than the other. The control strategy follows the following rules:

1. while a single phase is in conduction, the torque is controlled inside the main (the thinner inner) hysteresis band;

2. during the phase commutation the torque control is performed as follows:

- for the formerly conducting phase the thinner hysteresis band is imposed;

- for the next phase the larger outer hysteresis band is prescribed;

3. after the end of the commutation period the torque will be again controlled within the thinner hysteresis band.

Upon the value of the torque relatively to the two hysteresis bands the voltages of the phases are commutated by soft chopping between three values: $+V_{d c}, 0$ and $-V_{d c}$.

To simulate the DITC system for the sample motor two look-up tables were built up upon FEA results [13].

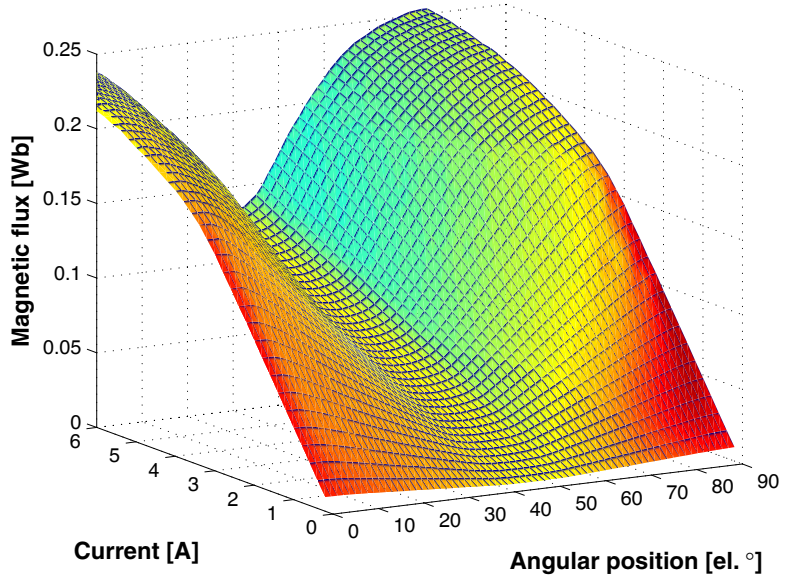

a) magnetic flux vs. phase current and rotor position

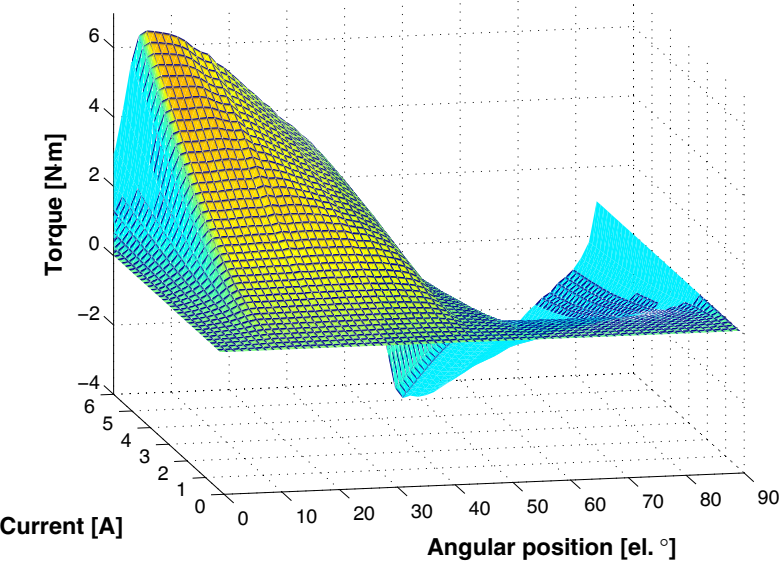

b) phase torque vs. phase current and rotor position

Fig. 3. The static characteristics of the modular SRM
They contain the magnetic flux and the torque, respectively, versus the phase current and the rotor position. Upon the values from the two look-up tables two 3D static characteristics for one phase of the modular SRM can be plotted (see Fig. 3).

The static characteristics of the magnetic flux are required only by the simulation program, while that of the total torque both by the control strategy implementation and the DITC system model.

The model of the DITC system controlled modular SRM was built up in the MATLAB ${ }^{\circledR} /$ Simulink $^{\circledR}$ environment. The main window of the simulation program is given in Fig. 4 .

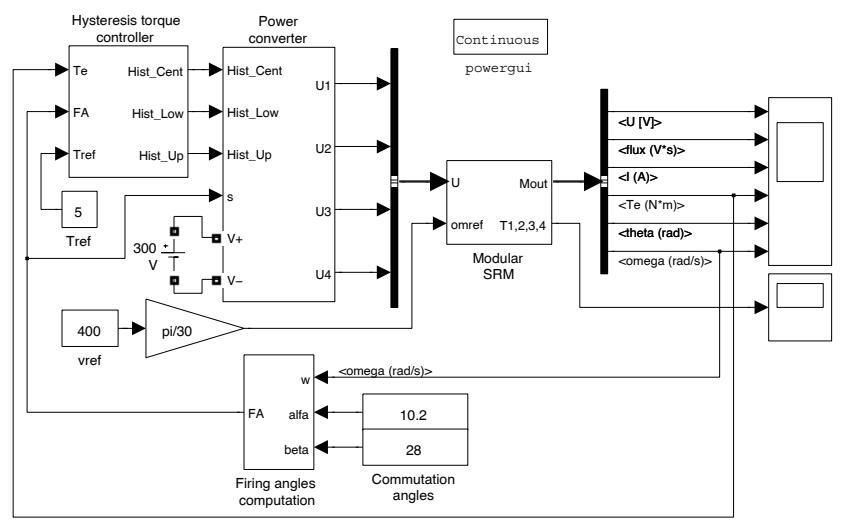

Fig. 4. The main window of the simulation program

As it can be seen the program is built up modularly. The blocks modeling the hysteresis torque controller, the four-phase power converter, the modular SRM and the firing angle computation unit all can be easily distinguished.

The Hysteresis torque controller subsystem is using three Relay type blocks, as shown in Fig. 5.

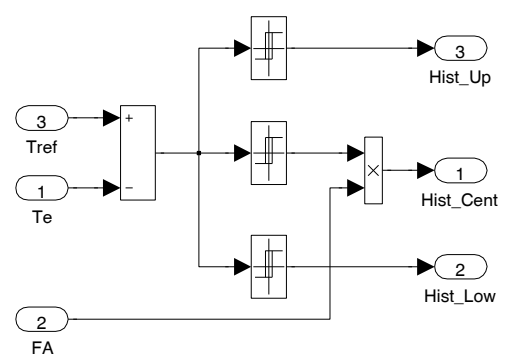

Fig. 5. The Hysteresis torque controller subsystem

The H-bridges of power converter were modeled by using blocks from the SimPowerSystems library of Simulink ${ }^{\circledR}$, as IGBT/Diode, etc. [32].

The model of the motor is based mainly on the two 2D look-up tables built up upon the static characteristics given in Fig. 3.

The simulations were performed under diverse conditions. Here some significant results obtained for the reference torque and speed of $5 \mathrm{~N} \cdot \mathrm{m}$ and $400 \mathrm{r} / \mathrm{min}$ are given. 
In Fig. 6 the total torque, the imposed one and that developed by the four phases of the modular SRM are given. As it can be seen the developed total torque is very close to the imposed $5 \mathrm{~N} \cdot \mathrm{m}$ reference torque. The torque ripples (of $12.45 \%$ ) are much smaller than in the case of a classical controlled modular SRM (near 30\% [10]).
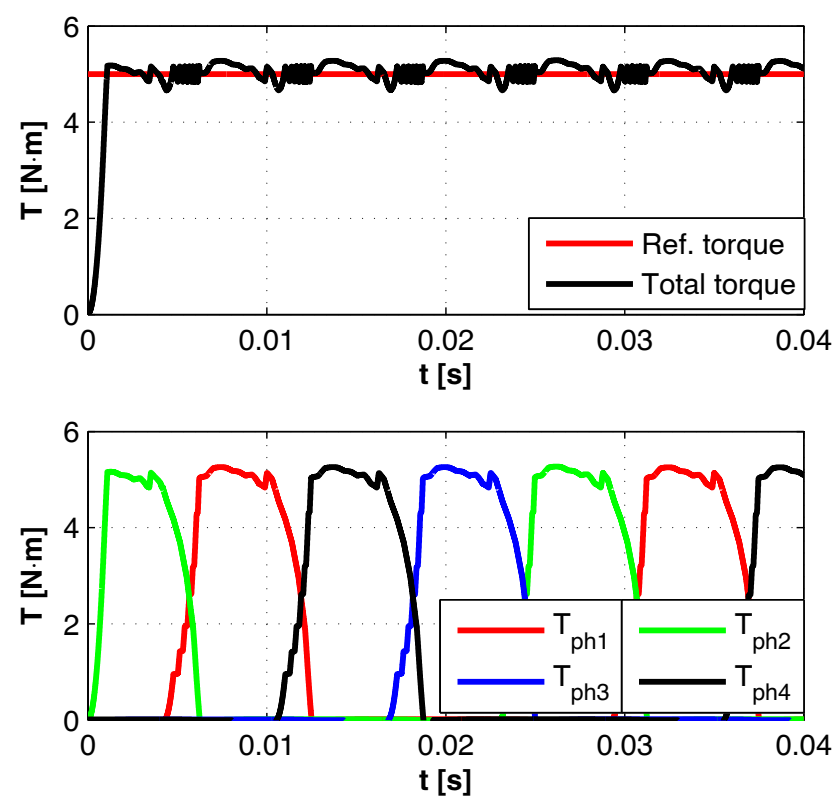

Fig. 6. Results of simulation: the total, the imposed and the phase torque developed by the modular SRM

In Fig. 7 a zoom of the above plots can be seen.
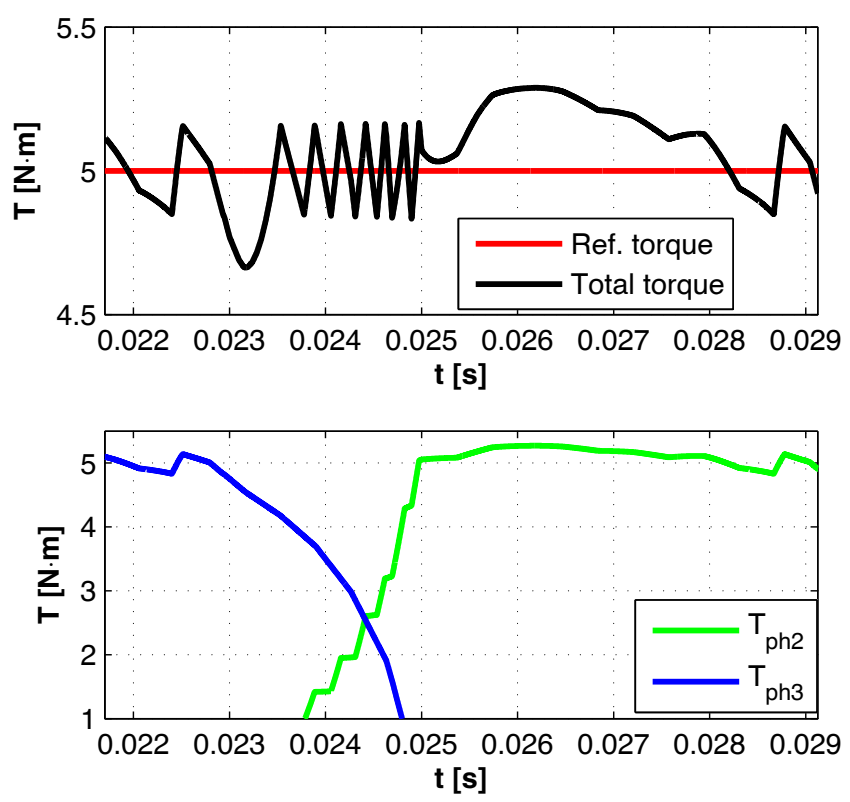

Fig. 7. Zoom of the results given in Fig. 6

In Fig. 8 also a zoom of the results given in Fig. 6 can be seen. It can be clearly observed how the instantaneous torque is kept within one of the two (inner and outer) hysteresis bands, upon the developed control strategy. Also the way as the dc voltage is chopped between the three values $\left(+V_{d c}, 0\right.$ and $-V_{d c}$ ) can be followed.
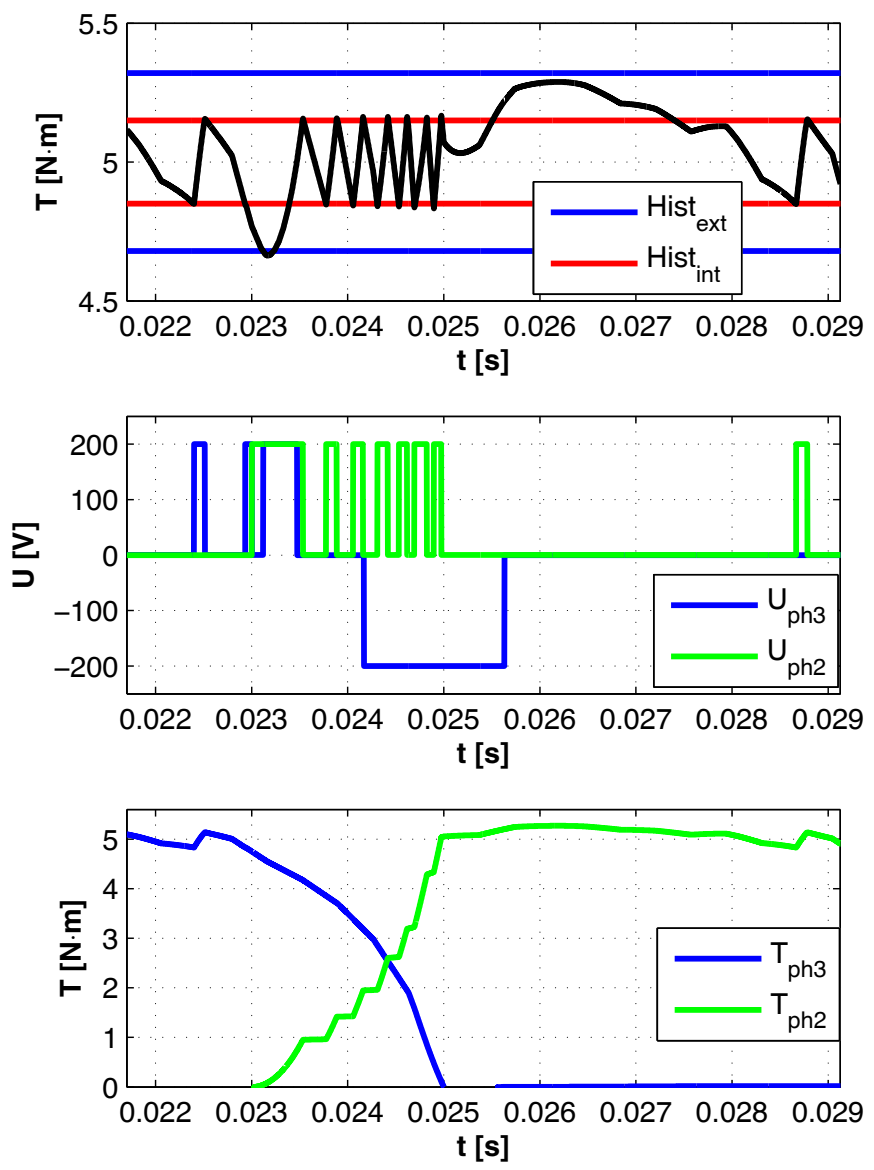

Fig. 8. Zoom of the results given in Fig. 6 showing the two hysteresis bands and the two phase voltages and torques during a commutation

In the figure the soft chopping of the voltage during the phase commutation can be also clearly observed. Before approximately $0.023 \mathrm{~s}$, while only phase 3 is in conduction, the torque is controlled inside the main (the thinner inner) hysteresis band. During the phase commutation, when usually the torque drops, the torque control is more permissive, since it is partially performed upon the thinner hysteresis band. For the period of commutation also the higher frequency of the voltage soft chopping is clearly visible. After the commutation took place the torque is tried to be kept again within the inner hysteresis band.

\section{CONCLUSIONS}

The paper deals with the control of a SRM having modular stator designed for advanced automotive applications.

The modular construction of the SRM simplifies both its manufacturing and repairing. The modules can be manufactured separately and the stator can be easily assembled. The machine can be quickly repaired if winding faults occur without removing it from the load. 
Its fault tolerance was proven in several previous papers [10], [13]. Therefore it can be used in diverse automotive appliances, but also in other safety-critical applications in the fields of advanced automation systems, medical, aerospace, military, etc.

In such demanding systems also the relatively high torque ripples of the SRMs could be an important drawback. Therefore a simple, but yet effective control approach was taken into study: the DITC technique. The principles of this strategy are detailed in the paper.

The control method has several advantages, as smooth torque generation, direct compensation of the inherent torque ripple during phase commutation, good steady state torque control accuracy, simplification of sets of control variables and reduction of tuning control variables. All these are emphasized in the paper by advanced simulations performed via a MATLAB ${ }^{\circledR} /$ Simulink $^{\circledR}$ model of the machine. The model was developed by using the static magnetic flux and torque characteristics versus current and rotor position, fetched from the FEA model. The converter of the SRM was built up by using blocks from the SimPowerSystems library of Simulink.

The presented results prove the effectiveness of the applied control method and hopefully will help the specialists working in this field to deepen their understanding in advanced control of the SRMs.

Future works include the fault tolerance study of the modular SRM under the proposed DITC. The control system will be implemented on a DSpace system. A real-time turn $\mathrm{ON}$ and OFF angle optimization will be also investigated, which hopefully will more smooth the torque. This way, the DITC method will be applicable on the entire speed range of the machine, even with the possibility to work at speeds above the rated one.

\section{ACKNOWLEDGMENT}

This work was supported in part by the Romanian National Authority for Scientific Research, CNDI-UEFISCDI, under PCCA project no. 191/2012 and under bilateral grant no. 647/2013 (in the framework of the "Romanian-Slovak Intergovernmental S\&T Cooperation Programme for 2013-2014").

\section{REFERENCES}

[1] M. Baleani, A. Ferrari, L. Mangeruca, A. Sangiovanni-Vincentelli, M. Peri, S. Pezzini, "Fault-tolerant platforms for automotive safetycritical applications," in Proceedings of the 2003 International Conference on Compilers, Architecture and Synthesis for Embedded Systems (CASES '03), San Jose (USA), 2003, pp. 170-177.

[2] M. Naidu, S. Gopalakrishnan, T.W. Nehl, "Fault-tolerant permanent magnet motor drive topologies for automotive x-by-wire systems," IEEE Transactions on Industry Applications, vol. 46, no. 2, pp. 841$848,2010$.

[3] G. Henneberger, I.A. Viorel, Variable Reluctance Electrical Machines. Aachen (Germany): Shaker Verlag, 2001.

[4] L. Szabó, R. Terec, M. Ruba, P. Rafajdus, "Reconfigurable fault tolerant control system for switched reluctance motors," Electrical and Power Engineering Frontier, vol. 1, no. 1, pp. 1-7, 2012.
[5] T. Raminosoa, B. Blunier, D. Fodorean, A. Miraoui, "Design and optimization of a switched reluctance motor driving a compressor for a PEM fuel-cell system for automotive applications," IEEE Transactions on Industrial Electronics, vol. 57, no. 9, pp. 2988-2997, 2010.

[6] S. Gopalakrishnan, A.M. Omekanda, B. Lequesne, "Classification and remediation of electrical faults in the switched reluctance drive," IEEE Transactions on Industry Applications, vol. 42, no. 2, pp. 479-486, 2006.

[7] I. Husain, A. Radun, J. Nairus, "Fault analysis and excitation requirements for switched reluctance-generators," IEEE Transactions on Energy Conversion, vol. 17, no. 1, pp. 67-72, 2002.

[8] A. Schramm, D. Gerling, "Evaluation and comparison of fault tolerant Switched Reluctance Machines for a specific application," in Proceedings of the $9^{\text {th }}$ Spanish Portuguese Congress on Electrical Engineering (9 CHLIE), Marbella (Spain), 2004.

[9] W. Ding, J. Lou, L. Liu, "Improved decoupled model of mutually coupled dual-channel SRM with consideration of magnetic saturation in dual-channel operation," IET Electric Power Applications, vol. 7, no. 6 , pp. $427-440,2013$.

[10] L. Szabó, M. Ruba, "Segmental stator switched reluctance machine for safety-critical applications," IEEE Transactions on Industry Applications, vol. 48, no. 6, pp. 2223-2229, 2012.

[11] E. Martínez, P. Andrada, B. Blanqué, M. Torrent, J. Perat, J. Sánchez, "Environmental and life cycle cost analysis of a switched reluctance motor," in Proceedings of the $18^{\text {th }}$ International Conference on Electrical Machines (ICEM'2008), Vilamoura (Portugal), 2008, pp. $1-4$.

[12] L. Szabó, M. Ruba, D. Fodorean, "Study on a simplified converter topology for fault tolerant motor drives," in Proceedings of the $11^{\text {th }}$ International Conference on Optimization of Electrical and Electronic Equipment (OPTIM '2008) 2008, pp. 197-202.

[13] M. Ruba, I.A. Viorel, L. Szabó, "Modular stator switched reluctance motor for fault tolerant drive systems," IET Electric Power Applications, vol. 7, no. 3, pp. 159-169, 2013.

[14] S.J. Evangeline, S.S. Kumar, "Torque ripple minimization of switched reluctance drives - A survey," in Proceedings of the $5^{\text {th }}$ IET International Conference on Power Electronics, Machines and Drives (PEMD '2010) Brighton (UK), 2010.

[15] I. Husain, "Minimization of torque ripple in SRM drives," IEEE Transactions on Industrial Electronics, vol. 49, no. 1, pp. 28-39, 2002.

[16] Y. Sozer, I. Husain, D.A. Torrey, "Advanced control techniques for switched reluctance machine drives in emerging applications," in Proceedings of the 2013 IEEE Energy Conversion Congress and Exposition (ECCE '2013), Denver (USA), 2013, pp. 3776-3783.

[17] G. Baoming, W. Xiangheng, J. Jingping, "Nonlinear internal-model control for switched reluctance drive with torque ripple-free," Automatika, vol. 43, no. 1, pp. 2-13, 2002.

[18] M.J. Navardi, B. Babaghorbani, A. Ketabi, "Efficiency improvement and torque ripple minimization of switched reluctance motor using FEM and seeker optimization algorithm," Energy Conversion and Management, vol. 78, no. 2, pp. 237-244, 2014.

[19] M.S. Islam, J. Husain, "Torque-ripple minimization with indirect position and speed sensing for switched reluctance motors," IEEE Transactions on Industrial Electronics, vol. 47, no. 5, pp. 1126-1133, 2000.

[20] R. Gobbi, K. Ramar, "Optimisation techniques for a hysteresis current controller to minimise torque ripple in switched reluctance motors," IET Electric Power Applications, vol. 3, no. 5, pp. 453-460, 2009.

[21] V. Petruş, A. Pop, C. Marţiş, V. Iancu, J. Gyselinck, "Direct instantaneous torque control of SRMs versus current profiling Comparison regarding torque ripple and copper losses," in Proceedings of the $12^{\text {th }}$ International Conference on Optimization of Electrical and Electronic Equipment (OPTIM'2010), Moieciu (Romania), 2012, pp. 366-372.

[22] R. Mitra, W. Uddin, Y. Sozer, I. Husain, "Torque ripple minimization of switched reluctance motors using speed signal based phase current 
profiling," in Proceedings of the $3^{\text {rd }}$ Annual IEEE EnergyTech Conference, Cleveland (USA), 2013, pp. 1-5

[23] M. Dowlatshahi, S.M.S. Nejad, J.-W. Ahn, "Torque ripple minimization of switched reluctance motor using modified torque sharing function," in Proceedings of the $21^{\text {st }}$ Iranian Conference on Electrical Engineering (ICEE '2013), Mashhad (Iran), 2013, pp. 1-6.

[24] J. Sun, F. Bai, W. Lou, F. Sun, "Direct instantaneous torque control combined with torque sharing function strategy for switched reluctance drive," in Proceedings of the $3^{\text {rd }}$ International Conference on Intelligent Control and Information Processing (ICICIP'2012), Dalian (China), 2012, pp. 386-389.

[25] N.H. Fuengwarodsakul, R.W. De Doncker, "Instantaneous torque controller for switched reluctance vehicle propulsion drives," in Proceedings of the $20^{\text {th }}$ Electric Vehicle Symposium (EVS20), Long Beach (USA), 2003.

[26] J. Sun, Y. Wang, F. Bai, F. Sun, "Simulation of the direct instantaneous torque control of SRM using MATLAB," in Proceedings of the Automatic Control and Artificial Intelligence Conference (ACAI '2012) Xiamen (China), 2012, pp. 1850-1853.

[27] M. Ruba, D. Fodorean, "Design, analysis and torque control of low voltage high current SRM for small automotive applications," in
Proceedings of the IEEE Region 8 EUROCON Conference (EUROCON '2013), Zagreb (Croatia), 2013, pp. 1498-1503.

[28] T. Husain, A. Elrayyah, Y. Sozer, I. Husain, "An efficient universal controller for switched-reluctance machines," in Proceedings of the $28^{\text {th }}$ Annual IEEE Applied Power Electronics Conference and Exposition (APEC '2013), Long Beach (USA), 2013.

[29] R.B. Inderka, R.W. De Doncker, M. Krehenbrink, "On-line estimation of instantaneous torque in switched reluctance machine control," in Proceedings of the 2000 IEEE International Symposium on Industrial Electronics (ISIE '2000), Cholula (Mexico), 2000, pp. 385-389.

[30] M. Kuczmann, A. Iványi, The Finite Element Method in Magnetics. Budapest (Hungary): Akadémiai Kiadó, 2008.

[31] B. Jeong, K. Lee, J. Na, G. Cho, H. Baek, "Direct torque control for the 4-phase switched reluctance motor drives," in Proceedings of the $8^{\text {th }}$ International Conference on Electrical Machines and Systems (ICEMS '2005), Nanjing (China), 2005, pp. 524-528.

[32] V. Hrabovcová, P. Rafajdus, M. Lipták, L. Szabó, "Performance of converters suitable for switched reluctance generator (SRG) operation," Journal of Electrical Engineering, vol. 64, no. 4, pp. 201-211, 2013. 